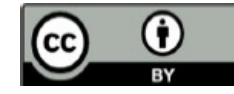

\title{
Determining Professional Mobility Levels of Secondary School Teachers
}

\author{
Gulnara Ismailova1 ${ }^{\text {* }}$ Alma Mamanova², Gulbarshyn Aypova ${ }^{3}$, Nurgul Begaliyeva4$^{4}$, Sarash Konyrbayeva4, Malik Sultanbek ${ }^{5}$
}

${ }^{1}$ L.N. Gumilyov Eurasian National University, Nur-Sultan, Kazakhstan; e-mail: wclta.info@gmail.com

${ }^{2}$ S. Seifullin Kazakh Agro Technical University, Nur-Sultan, Kazakhstan; e-mail: alma_m_75@mail.ru ${ }^{3}$ Kazakh Humanitarian Law University, Semey, Kazakhstan; e-mail: gulbarshin63@mail.ru

${ }^{4}$ Kazakh National Women's Teacher Training University, Almaty, Kazakhstan; e-mail: zhantanu@mail.ru; pedsheberlik@mail.ru

${ }^{5}$ Khoja Akhmet Yassawi International Kazak-Turkish University Deputy Dean of the Preparatory Faculty, Kazakhstan, Turkistan; e-mail: malik.sultanbek@ayu.edu.kz

\begin{abstract}
Education has a great share in the development of a country. Countries that invest in education are developing in all respects. There are many factors that affect education, but the most important of them is the teacher. Because other factors affecting education do not make sense without a teacher. The better the teachers are trained, the more appropriate the working conditions, the better the quality of education, and thus the establishment of a modern, peaceful country. This study aims to determine professional mobility levels of secondary school teachers. Mixed research method was used in the study. A total number of 146 teachers including 60 teachers in the control group and 86 in the experimental group participated in the study. Results confirmed the effectiveness of activities to update students' pedagogical experiences as a necessary step in the development of professional pedagogical mobility. Results are discussed with relevant literature and recommendations for further research and practices are provided.
\end{abstract}

Keywords: Professional mobility, secondary school teachers, mixed research.

\section{Introduction}

The current concept of professional mobility of a person as the ability to change a profession or type of activity in conditions of high dynamism of social relations and connections also implies the ability for successful self-realization in the social (household, family, confessional, ethnic, etc.) environment. However, mobility, being one of the main indicators of the subject's professional and social relevance, acts simultaneously as a value-semantic construct, as a type of personality response to a situation in changing conditions of life activity (Buchan et al., 2014; Lisaite, 2012; Karpovich et al., 2019).

The development of the concept of "competence" is at the intersection of interests of sociology, history, cultural studies, cognitive psychology, personality psychology and social psychology. The problem of identifying the "self" was solved in Western psychology by Adler, James, Parfitt, Freud, Habermas, Heidegger, Horney, Jung, Erickson, in Soviet science; Abramenkova, Bakhtin, Kon, Mukhina, Popova (Gonzalez-Rey, 2014). In other words, cross-cultural training facilitates developing the above listed skills in professionals with high mobility levels. Importantly, Black and Mendenhall (1990) take these three dimensions, namely, the self, relationship, and perception dimensions and analyse how cross-cultural training improves the well-being of these professionals. As far as the self-dimension is concerned, crosscultural training manages to raise the individuals' levels of confidence in themselves and their ability to act effectively in a cross-cultural setting. Presbitero and Toledano (2018) argued that cross-cultural training helps to enhance the skills required to establish effective relationships with members of other cultures and therefore the relationship dimension is positively affected. Finally, cross-cultural training also carries important implications as far the perception dimension is concerned. Throughout cross-cultural training professionals with higher mobility receive information about how people of other cultures view the world as well as their cognitive tendencies. Importantly, cross-cultural training provides mobile professionals with an opportunity to learn some culture - and communication-related patterns that they may use as the basis for acquiring an adequate perception of the host culture (Zhou, 2017; Kamal-Abdien and Jacob, 2019; Demirel, Turkel and Aydın, 2020).

The concept of self-efficacy has been the subject of many studies in the field of education today.

*Corresponding author: wclta.info@gmail.com 
The main reason why the concept of self-efficacy is so prominent in educational research is that students' perceptions of self-efficacy have a positive effect on motivation and learning, and at the same time, teachers' perceptions of self-efficacy are a teacher characteristic that directly affects students' success. In other words, the perception of self-efficacy of both students and teachers is seen as the key to academic success and other learning products.

The concept of self-efficacy was first put forward in Bandura's Social Cognitive Theory and defined as the beliefs of individuals about their ability to perform at the desired level (Bandura, 1994). Self-efficacy beliefs are much more important than the abilities and skills used by individuals because they affect how individuals feel, think, motivate, and behave. It is not enough for individuals to have the knowledge and skills necessary to accomplish a job, but also to have beliefs that they can successfully perform the desired behaviors even in challenging and typical conditions. There are various types of competencies which are mentioned as follows (Birisci and Kul, 2019): the body,

- Psychophysiological - unity and continuity of physiological and mental processes and structure of

- Social - a system of properties by which an individual becomes a social individual, a member of a community, a group, and involves the division of individuals according to their social class, social status, and learned norms,

- Personal - the unity and continuity of life, goals, motives, life-meaning attitudes of a person who is aware of himself as the self.

Professional competence, along with ethnic competence, is the most popular type of social competence in modern conditions. The change in the socio-economic way of life of society is accompanied not only by a change in social roles, but also by the appearance of new requirements for the profession and organization of activities. Socio-economic conditions affect all spheres of society. Therefore, there are new requirements for a professional (Epstein and Hundert, 2002).

Competence implies conscious attention to the question "Who Am I?", which accompanies a person throughout his life and on the answer to which much depends in professional activity. Therefore, the growing interest in the problem of professional competence is a reaction to changing socio - economic conditions and new requirements for training professionals. The dual goal of education, which is to focus on the qualitative assimilation by students of the necessary content, on the one hand, and on the other hand to focus on the development teachers' personal qualities who are able to transform pedagogical reality and himselfherself in accordance with the requirements of a developing society. The specifics of the teaching profession suggest that its carrier is at the center of all social events and in a situation of constant social assessment (Koc and Arslan, 2017; Tenekeci and Uzunboylu, 2020).

On the one hand, society assesses individuals' activities, helshe assesses others because of the professional duties. In a rural school environment, the situation of mutual evaluation has enough importance. Among the many features of pedagogical activities, the main one is an object of imitation is a teacher. The trainees adopt not only the manner of his appearance and behavior, but also the style of activity and communication, the nature of his attitude towards the world around him, towards the assigned work, towards other people, towards himself. This means those people who today are engaged in the education and upbringing of the younger generation are specialists which are trained in other socioeconomic, political, professional and cultural conditions, in which other socio-cultural codes and values were dominated).

Moreover, only a person with higher mobility levels can grow up people with higher mobility levels. The system of additional vocational education which possesses qualified staffs as well as flexibility in building advanced training programs (professional retraining) and trajectories of individual teacher development can solve the problem of developing teachers' professional mobility at the postgraduate stage. These tasks are designed to provide a developing section of pedagogical science about adult education - andragogy (pedagogical science about adult education - andragogy) (Holmes and AbingtonCooper, 2000). It is recognized that the process of professional mobility in the process of self-development is not only of personal interest, but also of social requirements. Self-discipline is a person's conscious self-development, and it demonstrates the requirements, goals, interests that are created by a strong and capable society (Alexandrovet al., 2011; Jung, Zhou and Lee, 2017).

Kiselev and Kiseleva (2015) argued that self-actualization is fundamentally self-evident in selfactualizing ways and features that can lead to higher education. Malyavskaya et al. (2016) stated that child's self-improvement behavior develops at the early ages, and when he is a grown-up, it has to be at the most important place. The role of the society is to enable this activity to be realized. In addition, the main directions of the professional mobility pedagogy are the formation of the communicative abilities, the aspiration to self-development that helps students to engage in creative activities. 
The above-mentioned guidelines are the basis for determining the goals and objectives of our study. In addition, the urgency of the problem is connected with the need to form a package of strategic vectors for postgraduate vocational education with a focus on training a mobile specialist, as evidenced by the use of the concepts "mobile personality", "mobile specialist", "professional mobility" in almost all national educational concepts and doctrines. At the same time, in this circumstance, a certain paradox and inconsistency of the "mobility" phenomenon can be seen, expressed in the frequent use of the concepts of this terminological series in the scientific circulation and insufficiently studied essence of the phenomenon itself (Edwards-Jr, Le and Sustarsic, 2020).

The priority of personal meanings and values of subjects of educational activities creates the need to take into account the whole variety of individual characteristics and pedagogical experience. Therefore, the focus on the development of professional mobility of a teacher requires the identification and study of its components in order to maximize the individualization of the process of productive mastering the content of teacher education and its rational, dynamic use in professional activities. Therefore, this study aims to determine professional mobility levels of secondary school teachers.

\section{Materials and Methods}

In this part of the study, the research model, study group, data collection tools, data collection, statistical techniques used in data analysis and interpretation, and related explanations were examined separately within the scope of quantitative and qualitative aspects.

\section{Research Model}

In this study, a mixed method, in which both quantitative and qualitative data are used together, was preferred to increase the reliability of the results. Using this technique in researches is more effective in solving problems than using qualitative and quantitative techniques alone (Creswell and Clark, 2007).

\section{Participants}

A total number of 146 teachers including 60 teachers in the control group and 86 in the experimental group participated in the study.

\section{Data Collection}

Private empirical methods were complemented by research and exploratory work, a pedagogical experiment which includes diagnostics, a statement of facts and phenomena, experiential learning, and teaching, forecasting the prospects for the development of additional professional education. Experimentally tested specially designed criterion-assessment tools for diagnosing the formation of professional mobility of a teacher, allowing not only to track its dynamics in general, but also to identify diagnosis trends at the intermediate stages in order improve the qualities that make up professional mobility (activity, creativity and mobility). The subjects of the research are teachers (146) of secondary school No. 20 of Almaty region.

To solve problems of developing conceptual foundations and implementing the practice of forming professional mobility of a teacher, a set of mixed methods were applied in the study:

1) Qualitative research methods which include:

- An interdisciplinary analysis and data synthesis from philosophical, sociological, natural science, psychological and pedagogical literature.

- The historical and methodological analysis (including the study of documents: doctrines, concepts, regulations, educational programs of regional and federal levels).

- The analysis of foreign and domestic psychological and pedagogical experience on the formation of a mobile personality in educational systems.

- The compilation of the research work results in order to identify patterns of formation of the studied phenomenon, etc.

2) Experimental methods included:

- Students' oral and written interviews, analysis of the products activities.

- Method of expert assessments and self-assessments.

- Statistical methods for processing research results and methods for their interpretation.

During the experiment, an interview was carried out with educators. The interview form included 16 questions. If you have 55 or more scores, this means you are actively involved in your profession, 36 to 54 points indicate that your professional mobility is not successful; the result of lower scores indicates 
that the stage of professional mobility has stopped and the scores were based on Likert-type scale is 1-5 points. The questions in the survey are provided below.

1. I try to make myself active.

2. Although I am busy, I leave a lot of time left for development.

3. Resolving barriers increases my activity.

4. I always make feedback to myself; it helps me to adjust and evaluate myself.

5. I always value my work and spend a lot of time on it.

6. I analyze my feelings and experiences and share the positive outcomes with my colleagues.

7. I read a lot, look for new ones, and get the necessary feedback from myself.

8. I discuss interesting questions for myself widely.

9 . I believe in my abilities.

10. I try to be more open-minded.

11. I feel the impact of my environment.

12. I manage my professional mobility and get good results from it.

13. I am always delighted with the new ones.

14. The growth of responsibility does not frighten me

15. I look after the growth of my carrier.

16. My self-improvement is based on my new vision of my profession.

\section{Data Analysis}

SPSS 22.0 statistical program was used to analyze the quantitative data of the study. Frequency and content analysis techniques were used to analyze the data related to the qualitative dimension of the study. While analyzing the data obtained from the participants, the confidentiality principle was taken into consideration, the names of the participants were not used, and each participant was coded. The answers given were examined in detail and the setting was coded separately by two different researchers. Afterwards, common codings were determined by combining the codings made and the necessary arrangements were made. It was then presented to a specialist. Yildirim and Simsek (2005) state that it is important for an external expert to examine the data collection tools, raw data, coding at the analysis stage and reporting process in order to ensure the verification and reliability of the studies conducted in qualitative research.

\section{Results}

One hundred and forty-six teachers participated in the experiment. However, during the experiment the teachers were guided. Sixty teachers were in control group and 86 attended the experimental group. In the control group, the percentage of pedagogical activity was $30.3 \%$, in experimental group - 28.8. The creativity was determined by CG-21\%, the experimental group $-27.2 \%$. The survival rate was $25.2 \%$, and the experimental group was $24 \%$.

Table 1

Implementation diagnosis of the teacher professional mobility

\begin{tabular}{ccccccccc}
\hline \multirow{2}{*}{ Group } & \multirow{2}{*}{ Number } & \multicolumn{2}{c}{ Activity } & \multicolumn{2}{c}{ Creativity } & \multicolumn{2}{c}{ Mobility } & X average score \\
\cline { 3 - 8 } & & Number & $\%$ & Number & $\%$ & Number & $\%$ & Number \\
БT & 60 & 16 & 26,6 & 24 & 25 & 20 & 30 & 0,84 \\
ЭT & 86 & 27 & 31,3 & 34 & 40,9 & 25 & 29,0 & \\
\hline
\end{tabular}

The results of the decisive experiment demonstrate that the low level of implementation of the teachers' professional mobility mechanisms has been insufficient. It has given rise to the need for theoretical knowledge and practical skills to address the issue of the professional mobility of the teaching community. That is why we, the pedagogical staff, have organized our five-day (about 36-hour) pedagogical quintet with "I support the new".

After the pedagogical quintet, the survey was taken again. From this point of view, we can see that the level of professional mobility of pedagogical professionals has improved, the percentage of personal 
qualities has increased. It is noticed from the table below (Table 2).

The experimental work carried out revealed the effectiveness of the didactic system for the teachers' professional mobility development at the postgraduate education stage and based on an analysis results which describe the implementing mechanisms for the methodological potential of the developed system.

Table 2

Comparative table of results of "the implementation diagnosis of the teacher professional mobility"

\begin{tabular}{ccccc}
\hline Group & $\begin{array}{c}\text { Before } \\
\text { experiment }\end{array}$ & $\begin{array}{c}\text { Control group 1 } \\
\text { After experiment }\end{array}$ & $\begin{array}{c}\text { Experimentative group 1 } \\
\text { Before experiment }\end{array}$ & \begin{tabular}{c} 
After experiment \\
\hline Activity
\end{tabular} $3^{33,9}$ \\
Creativity & 27,2 & 35 & 22 & 38 \\
Mobility & 38,9 & 28,8 & 42,1 & 51,4 \\
\hline
\end{tabular}

In the experimental didactic system structure, the target, meaningful and procedural characteristics of the educational process were exposed to innovative changes. The main characteristic and didactic unit of the learning process within this technology is the educational and professional situation, which is part of a set of multi-level professional-oriented tasks and assignments for students of the Institute for Advanced Studies and Professional Retraining, following which each student updates pedagogical experience and mobilizes professionally significant qualities to solve educational-professional problems.

\section{Discussion}

Results of the study revealed that the modern scientific basis for the development and theoretical and methodological description, conceptual and substantive-technological approaches to the teachers' professional mobility development problem in the additional pedagogical education sphere is the importance of solving this problem since this determines the efficiency and quality of the educational process at all levels. The pedagogical essence of professional mobility of teachers in the educational sphere is defined.

The teachers' integrative personal quality is expressed in prompt response to the situation of professional pedagogical activity through the mobilization of all external and internal resources. The structural components of professional mobility are identified, which act individually and in systemic unity as the most important targets of the teacher's professional development in the institutions of advanced training and professional retraining of educators. This is consistent with previous studies which believe personal activity that leads to personal development begins with the appearance in early childhood and then sets the task of self-change in accordance with the individual tasks of self-employment in the form of methods that can lead to the development of intellectual and emotional well-being of the individual. It is important to fully agree with this statement that it is important for the teacher to create professional mobility and set the task to bring it to a new qualitative level. Vorotnykova (2015) claimed that when a person sets new goals for his advancement, a new integrity, new dimensions then development can take place. The formation of personality is a kind of self-determination, self-expression, and a special kind of development prospects (Tkach, 2019). The key point here is that the main human need to be mobile. A significant contribution to the development of the professional readiness and specialists' creative activities is the development of their basic and special competences as the basis of mobility in professional activitieslt provided the communication of cooperation in terms of technology. The pedagogical importance and competencies of teachers are supported by these studies.

It was figured out that educational activities in the system of additional education, aimed at developing the qualities of a mobile person, and most successfully carried out based on managed self-education principle. The set of substantiated didactic provisions of adult education which is arising from the essence of andragogical approaches to education determines the content and the usage of the technological support and totality, moreover, it is aimed at activating personally developing learning environment and students' cognitive independence. The patterns of teachers' professional mobility development were identified at a particular stage of his professional development and laid the basis for the design of the educational process in the additional professional education system as seen in Huggenberger et al. (2011).

The nature of professional mobility in the aggregation of social and biological factors that determine 
its development is manifested in an objective pedagogical reality through the specific multifunctional activity of a teacher. Its main feature is not so much contentedness and even not the special nature of relationships within it, but, above all, the semantic aspect of pedagogical activity, since the meaning is the motivational basis and essence of pedagogical work, stimulates the processes of self-development and self-realization of the teacher. In this regard, in the work of professional mobility is seen as a valuesemantic construct of the person, as an all-encompassing mental reality, which allows to combine knowledge, skills, experience, orientation, personal qualities and abilities of a teacher into a single whole and reflecting the highest level of professional achievements of a person. From this perspective, mobility of a subject activity is the main indicator of personal professional development, and its essential forces at all stages of vocational training, and, above all, in the system of additional pedagogical education, which is most integrated into the professional and pedagogical environment (Tilak and Mathew, 2016).

Teachers' mobility qualities are not limited in sphere of purely pedagogical activities. In conditions when society is experiencing a global financial and economic crisis, which sometimes turns into a political crisis, teacher as a citizen and an active participant in social and political processes acts as a fighter against immorality, social injustice, and political myopia. In this struggle, mobility as personality traits reinforce the civic qualities of the teacher (Kerssen-Griep, 2001). Accordingly, the fundamental position is that the development of a professionally mobile personality as a whole is possible in the space of a holistic pedagogical process based on the activation of a set of conditions within a specially created didactic system corresponding to the functional properties of both the phenomenon under study and professional activity, which reaches a new quality level mobility of the subject of this activity.

\section{Conclusion}

In the experimental didactic system structure, the target, substantive and procedural components of the educational process were tested in the implementation context of the controlled self-education technology of educational staff. Using as the main characteristic and didactic unit of the learning process within the framework of this technology, the educational and professional situation included in the complex of multi-level professional-oriented tasks and assignments for students of the Institute for Advanced Studies and Professional Retraining. It confirmed the activities effectiveness to update the students' pedagogical experience as a necessary stage on the vocational pedagogical mobility development.

The analyzed results allowed to conclude that the implementation of the proposed didactic system based on the use of the principle and technology of adults' managed self-study contributes to the achievement of higher results than in the traditional educational process. Experimental verification of the pedagogical quintet developed program was carried out which finally confirmed the effectiveness of the didactic system and allowed to practically confirm the theoretically revealed features of the teacher's professional mobility development.

The study does not exhaust the entire complexity of the problem. Further research is needed in which more attention will be paid to scientific research and the study of psychological mechanisms affecting the pedagogical process of developing professional mobility. It can be recommended for further researches to examine the relationship on this quality development with various professional socialization factors of teachers. The direction of further research can also be the development of technologies for the purposeful formation and teachers' professional mobility in the study of specific courses and disciplines at various levels of the educational system. It requires the development of special measures set to assist young teachers in professional self-determination, support and develop their professional preparations and mobility.

\section{Acknowledgment}

We would like to thank to the all people who have contributed to the realization of this study.

\section{Conflict of interests}

The authors declare no conflict of interest.

\section{References}

Alexandrov, E. V., Blatov, V. A., Kochetkov, A. V., \& Proserpio, D. M. (2011). Underlying nets in three-periodic coordination 
Ismailova G. et al. (2020). Determining professional mobility levels of secondary school teachers, International Journal of Cognitive Research in Science, Engineering and Education (IJCRSEE), 8(3), 39-45.

polymers: Topology, taxonomy, and prediction from a computer-aided analysis of the Cambridge Structural Database. CrystEngComm, 13(12), 3947-3958. http://dx.doi.org/10.1039\%2Fc0ce00636j

Bandura, A. (1994). Self-efficacy. In V. S. Ramachaudran (Ed.), Encyclopedia of human behavior, 4, pp. 71-81. New York: Academic Press. https://doi.org/10.1002/9780470479216.corpsy0836

Birisci, S., \& Kul, E. (2019). Predictors of technology integration self-efficacy beliefs of preservice teachers. Contemporary Educational Technology, 10(1), 75-93. https://doi.org/10.30935/cet.512537

Black, J. S., \& Mendenhall, M. (1990). Cross-cultural training effectiveness: A review and a theoretical framework for future research. Academy of Management Review, 15(1), 113-136. https://doi.org/10.5465/amr.1990.11591834

Buchan, J., Wismar, M., Glinos, I. A., \& Bremner, J. (2014). Health professional mobility in a changing Europe. New dynamics, mobile individuals, and diverse responses. Geneva: World Health Organization. Retrieved from https://apps.who.int/ iris/bitstream/handle/10665/326372/9789289050258-eng.pdf

Creswell, J. W. \& Clark, V. L. P. (2007). Designing and conducting mixed methods research. Australian and New Zealand Journal of Public Health, 31(4), 388-389. https://doi.org/10.1111/j.1753-6405.2007.00096.x

Demirel, M., Turkel, A., \& Aydın, I. (2020). Speaking self-efficacy beliefs of Turkish university students. Cypriot Journal of Educational Sciences, 15(3), 399-411. https://doi.org/10.18844/cjes.v15i3.4905

Edwards-Jr, D. B., Le, H., \& Sustarsic, M. (2020). Spatializing a global education phenomenon: Private tutoring and mobility theory in Cambodia. Journal of Education Policy, 35(5), 713-732. https://doi.org/10.1080/02680939.2019.1610192

Epstein, R. M., \& Hundert, E. M. (2002). Defining and assessing professional competence. Jama, 287(2), 226-235. https://doi. org/10.1001/jama.287.2.226

Gonzalez-Rey, F. L. (2014). Advancing further the history of Soviet psychology: Moving forward from dominant representations in Western and Soviet psychology. History of Psychology, 17(1), 60-67. Retrieved from https://psycnet.apa.org/ doi/10.1037/a0035565

Holmes, G., \& Abington-Cooper, M. (2000). Pedagogy vs. andragogy: A false dichotomy? Pedagogy, 26(2), 17-26. https://doi. org/10.21061/jots.v26i2.a.8

Huggenberger, R., Siddiqui, S. S., Brander, D., Ullmann, S., Zimmermann, K., Antsiferova, M., \& Detmar, M. (2011). An important role of lymphatic vessel activation in limiting acute inflammation. Blood, The Journal of the American Society of Hematology, 117(17), 4667-4678. https://doi.org/10.1182/blood-2010-10-316356

Jung, K. R., Zhou, A. Q., \& Lee, R. M. (2017). Self-efficacy, self-discipline, and academic performance: Testing a contextspecific mediation model. Learning and Individual Differences, 60, 33-39. https://doi.org/10.1016/j.lindif.2017.10.004

Kamal Abdien, M., \& Jacob, M. (2019). Cross-cultural training and cultural intelligence of hospitality students: a case study in Egypt and Spain. Journal of Teaching in Travel \& Tourism, 19(3), 191-215. https://doi.org/10.1080/15313220.2018.15 57098

Karpovich, N., Seidina, M. Z., Soboleva, E., Tikhonova, T., Pavlov, V., \& Takhumova, O. (2019). The problems of formation of social capital of socially vulnerable categories of the population in the modern metropolis. In International Conference on Man-Power-Law-Governance: Interdisciplinary Approaches (MPLG-IA 2019), Atlantis Press. https://dx.doi. org/10.2991/mplg-ia-19.2019.40

Kerssen Griep, J. (2001). Teacher communication activities relevant to student motivation: Classroom facework and instructional communication competence. Communication Education, 50(3), 256-273. https://doi.org/10.1080/03634520109379252

Kiselev, N. N., \& Kiseleva, E. V. (2015). Expert review of pedagogical activities at therapeutic recreation camps. Russian Education \& Society, 57(10), 830-837. https://doi.org/10.1080/10609393.2015.1148952

Koc, C., \& Arslan, A. (2017). Ortaokul ogrencilerinin akademik ozyeterlik algilari ve okuma stratejileri bilisustu farkindaliklari. Yuzuncu Yil Universitesi Egitim Fakultesi Dergisi, 14(1), 745-778. http://dx.doi.org/10.23891/efdyyu.2017.29

Lisaitè, D. (2012). Professional mobility. Journal of Intercultural Communication, 7(30), 1-17. Retreived from http://mail.immi. se/intercultural/nr30/lisaite.html

Malyavskaya, S. I., Kostrova, G. N., Lebedev, A. V., Golysheva, E. V., Muratova, A. P., Chudochin, V. P., \& Karpunov, A. A. (2016). Infants'provision with vitamin d in arkhangelsk region. Ekologiya cheloveka (Human Ecology), (11), 18-22. https://doi.org/10.33396/1728-0869-2016-11-18-22

Presbitero, A., \& Toledano, L. S. (2018). Global team members' performance and the roles of cross-cultural training, cultural intelligence, and contact intensity: the case of global teams in IT offshoring sector. The International Journal of Human Resource Management, 29(14), 2188-2208. https://doi.org/10.1080/09585192.2017.1322118

Tenekeci, F., \& Uzunboylu, H. (2020). Determining the relationship between the attitudes of private teaching institution teachers towards lifelong learning and their competence. International Journal of Learning and Teaching, 12(1), 1-16. https://doi. org/10.18844/ijlt.v12i1.4559

Tilak, J. B., \& Mathew, A. (2016). Promotion in academic profession in India: Upward mobility of teachers in higher education. Asia Pacific Journal of Educators and Education, 31, 85-113. http://dx.doi.org/10.21315/apjee2016.31.6

Tkach, M. (2019). Formation of The Professional Worldview of Future Music Teachers at Universities: A Theoretical and Methodological Analysis of The Problem. Individual Spirituality In Post-Nonclassical Arts Education, 31. http://oleksyuk. com/wp-content/uploads/2020/07/Kembridzh-II-vidannya-Individual-Spirituality-in-Post-nonclassical-Arts-Education. pdf\#page $=41$

Tuncay, S., \& Gokkaya, F. (2020). A meta review on parent training and therapies studies. Global Journal of Psychology Research: New Trends and Issues, 10(1), 102-117. https://doi.org/10.18844/gjpr.v10i1.4392

Vorotnykova, IP (2015). Introduction Of E-Learning in Postgraduate Pedagogical Education. Electronic Scientific Professional Publication "Open Educational E-Environment of The Modern University", (1), 15-20.

Yildirim, A., \& Simsek, H. (2005). Sosyal bilimlerde nitel arastirma yontemleri. [Qualitative research methods in the social sciencesi] Ankara: Seckin Yayincilik. http://eku.comu.edu.tr/index/2/2/etopkaya.pdf

Zhou, Z. (2017). Cross-cultural training and second language learning. Asian Education Studies, 2(3), 1-9. https://doi. org/10.20849/aes.v2i3.176 
Ismailova G. et al. (2020). Determining professional mobility levels of secondary school teachers, International Journal of Cognitive Research in Science, Engineering and Education (IJCRSEE), 8(3), 39-45. 